much smaller changes in ozone levels, up to $0.8 \%$ at $40 \mathrm{~km}$ altitude, and these changes are in phase with solar activity throughout the stratosphere and lower mesosphere.

Haigh et al. argue that the pattern of ozone change implied by SIM is consistent with ozone observations made by the Microwave Limb Sounder (MLS) instrument onboard the EOS Aura satellite ${ }^{7}$. They carried out a multiple-regression fit to MLS ozone data in the tropics at two altitudes, centred near $30 \mathrm{~km}$ and $55 \mathrm{~km}$. The regression predictors included two orthogonal indices of the tropical quasibiennial oscillation (QBO, a wind oscillation that dominates the tropical stratosphere and affects the abundance of ozone therein $)^{8}$ and a solar activity index (SIM irradiances averaged over $200-400 \mathrm{~nm}$ ). The resulting ozonesolar regression coefficient is positive at $30 \mathrm{~km}$ and negative at $55 \mathrm{~km}$, consistent with their model-based predictions.

If the assessment by Haigh and her colleagues ${ }^{2}$ is correct, the SIM observations would necessitate a re-evaluation of the mechanisms that produce solar variability, and how that variability affects the atmosphere. In addition to the impact on ozone, changes in SIM irradiance in the visible range, which are out of phase with the solar cycle, would require reconsideration of the role of solar variability in climate. Conventional wisdom ${ }^{9}$ holds that long-term increases in solar activity should warm the climate. But the opposite would be true if long-term irradiance variability behaved like that measured by SIM over the declining phase of solar cycle 23.
Should these results send researchers back to their laboratories to rethink their theories and rewrite their computer models? It is probably too early for that. It remains to be convincingly shown that the wavelength-resolved irradiance observations are accurate and, if they are, that they apply to periods other than the declining phase of solar cycle 23 .

In the first place, the length of the record used by Haigh et al. in their multiple-regression analysis is too short to yield unambiguous results: the two predictors used have timescales (28 months for the QBO, 11 years for the solar cycle) that are comparable to, or longer than, the length of the period analysed. Under these circumstances, there is no guarantee that multiple regression yields a physically meaningful apportionment of ozone variance among the predictors. Moreover, other regression analyses, based on ozone observations spanning more than 20 years $^{10,11}$, yield results that are broadly consistent with the conventional picture of solar variability. These analyses use data sets that do not extend much beyond the stratopause, the boundary - at about $50 \mathrm{~km}$ altitude - between the stratosphere and mesosphere. But they show no indication of a reversal in the sign of the relationship between solar activity and ozone levels in the upper stratosphere.

Haigh et al. ${ }^{2}$ point out that at present there is insufficient evidence to validate the SIM observations. In fact, we will probably need SIM irradiance data and independent ozone observations over a much longer period, at least the length of one solar cycle, before we can begin to be sure that the surprising irradiance variability measured by SIM does not arise from instrumental drifts or corrections thereof. Even if this is not the case, it will be necessary to reconcile the implications of the SIM observations with previous analyses of ozone changes during the 11-year solar cycle that are not consistent with the implied effects of SIM-like irradiance changes.

Rolando R. Garcia is in the Atmospheric Chemistry Division, National Center for Atmospheric Research, Boulder, Colorado 80305, USA.

e-mail:rgarcia@ucar.edu

1. Harder, J. W., Fontenla, J. M., Pilewskie, P., Richard, E. C. \& Woods, T. N. Geophys. Res. Lett. 36, L07801, doi:10.1029/2008GL036797 (2009).

2. Haigh, J. D., Winning, A. R., Toumi, R. \& Harder, J. W. Nature 467, 696-699 (2010).

3. Lean, J. Geophys. Res. Lett. 27, 2425-2428 (2000).

4. Krivova, N. A., Solanki, S. K. \& Floyd, L. Astron. Astrophys. 452, 631-639 (2006).

5. Krivova, N. A. \& Solanki, S. K. J. Astrophys. Astron. 29, 151-158 (2008)

6. Unruh, Y. C., Krivova, N. A., Solanki, S. K., Harder, J. W. \& Kopp, G. Astron. Astrophys. 486, 311-323 (2008).

7. Froidevaux, L. et al. J. Geophys. Res. 113, D15S20, doi:10.1029/2007JD008771 (2008).

8. Baldwin, M. P. et al. Rev. Geophys. 39, 179-229 (2001).

9. Lean, J. L. \& Rind, D. H. Geophys Res. Lett. 36, L15708, doi:10.1029/2009GL038932 (2009).

10.Randel, W. J. \& Wu, F. J. Geophys. Res. 112, D06313, doi:10.1029/2006JD007339 (2007).

11.Soukharev, B. E. \& Hood, L. L. J. Geophys. Res. 111, D020314, doi:10.1029/2006JD007107 (2006).

\title{
Spores ride a cooperative wind
}

This beautiful image of synchronized spore discharge from an ascomycete fungus comes from a book published in 1791. A cross-disciplinary group of researchers led by Marcus Roper and Agnese Seminara have now brought twenty-first-century approaches, including algorithms used to model the behaviour of droplets in clouds, to bear on study of this phenomenon (M. Roper et al. Proc. Natl Acad. Sci. USA doi:10.1073pnas.1003577107; 2010). They find that simultaneous discharge in itself creates an air flow, a cooperatively generated wind, that allows the spores to travel much farther than if ejected alone - so enhancing their prospects of wafting farther afield.

Roper, Seminara and colleagues used a combination of simulations, analytical models and experiments to investigate spore release from species of ascomycetes, in which spores develop in sacs (asci) in a cup-shaped structure called the apothecium. Their subjects included species of Sclerotinia (a plant pathogen) and Ascobolus (a dung fungus).
Spores of Sclerotinia, for example, have to rise from the fruiting body on the ground to infect plant flowers. In experiments, confirmed by simulations, spores riding a cooperative wind behaved much like "frictionless projectiles". They travelled 10 centimetres or more, with the range probably being limited by gravity, compared with the 3 millimetres of those ejected on their own, which are soon halted by viscous drag. Moreover, if the cooperative spore plume hit an obstacle (which in experiments was mimicked by a glass slide, but in a natural setting might be a leaf), pressure differences in the plume resulted in spore movement around it.

The authors also used high-speed imaging to see how spore release is coordinated, and looked at various apothecial species. Their data show that the process is self-organized. In Ascobolus, the process of ejection is initiated in a few asci, perhaps by a highly local change in air pressure. A wave of spore discharge across the apothecium then ensues, possibly driven by an alteration in

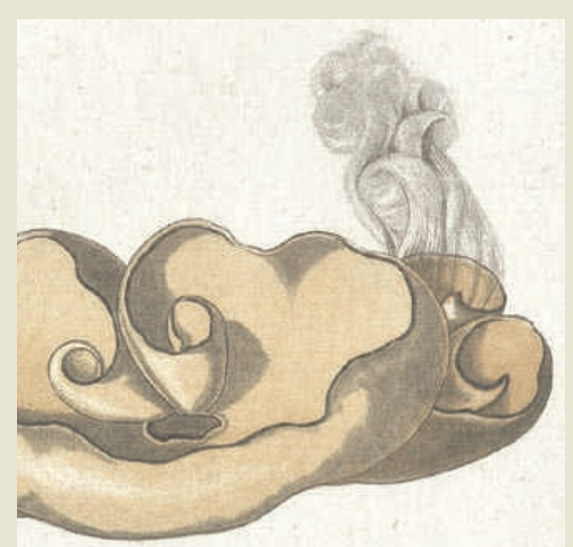

elastic stress, that may arise from changes in the turgor pressure of cells that are interspersed among the asci.

As well as the practical aspect of providing insight into the dispersal dynamics of a plant pathogen (the species studied, Sclerotinia sclerotiorum, infects and damages many different crops), there is another angle to this line of research. The authors point out that synchronized spore discharge might catch the fancy of biologists interested in the evolution of self-organized cooperative behaviour. Tim Lincoln 